\title{
Lunasin suppresses the migration and invasion of breast cancer cells by inhibiting matrix metalloproteinase-2/-9 via the FAK/Akt/ERK and NF-kB signaling pathways
}

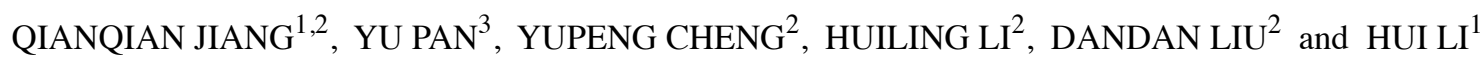 \\ ${ }^{1}$ Department of Biochemistry and Molecular Biology, Basic Medical Science College, Harbin Medical University, \\ Harbin 150081; ${ }^{2}$ Pharmaceutical College, Heilongjiang University of Chinese Medicine, Harbin 150040; \\ ${ }^{3}$ School of Environment and Chemical Engineering, Heilongjiang University of Science and Technology, \\ Harbin 150022, P.R. China
}

Received January 29, 2016; Accepted March 1, 2016

DOI: $10.3892 /$ or.2016.4798

\begin{abstract}
Lunasin is a naturally existing bioactive peptide with an Arg-Gly-Asp (RGD) motif, which competes with integrins to bind with the extracellular matrix (ECM) consequently suppressing the integrin-mediated signaling pathway. Owing to the RGD motif, lunasin has been proven as an effective anti-inflammatory, antitumor and antimetastatic agent in many types of cancer. However, knowledge of its inhibitory effect on metastasis and the related mechanism of action in breast cancer cells is limited. In this study, the inhibitory effect of lunasin on the proliferation, migration and invasion of two typical breast cancer cell lines, ER-negative MDA-MB-231 with $\alpha_{V} \beta_{3}$ expression and ER-positive MCF-7 with $\alpha_{V} \beta_{5} / \alpha_{5} \beta_{1}$ expression, were examined in vitro as well the related mechanisms. The results demonstrated that lunasin $(10-20 \mu \mathrm{M})$ effectively inhibited the migration and invasion activity and expression of matrix metalloproteinase (MMP)-2/-9 in both breast cancer cell lines. Meanwhile, we also found that lunasin inhibited the phosphorylation of focal adhesion kinase (FAK), Src, Akt, ERK and nucleus translocation of $\mathrm{NF}-\kappa \mathrm{B}$, which indicates that, possibly via competing with $\alpha_{\mathrm{V}} \beta_{3}$ or $\alpha_{\mathrm{V}} \beta_{5} / \alpha_{5} \beta_{1}$ integrin, lunasin suppresses the metastasis of breast cancer cells through integrin-mediated FAK/Akt/ERK and NF- $\mathrm{BB}$ signaling pathways followed by downregulation of the activity and expression of MMP-2/-9.
\end{abstract}

\section{Introduction}

Breast cancer is the most frequently diagnosed cancer and the leading cause of cancer-related death among females world-

Correspondence to: Professor Hui Li, Department of Biochemistry and Molecular Biology, Basic Medical Science College, Harbin Medical University, 194 Xuefu Road, Harbin 150081, P.R. China E-mail: huilihmu@163.com

Key words: lunasin, breast cancer, metastasis, FAK/Akt/ERK, $\mathrm{NF}-\mathrm{\kappa B}$ wide (1). In most cases, it is the metastasis of malignant tumor cells, rather than the primary solid tumor, that is the main cause of death (2). Metastasis is a complex process involving cell adhesion, migration, invasion and extracellular matrix (ECM) degradation. Hence, it is urgent to develop therapeutic strategies and agents with the ability to inhibit growth, migration, invasion and proteolytic degradation of ECM in breast cancer cells.

Integrin is a family of ubiquitous transmembrane glycoprotein receptors comprised of $18 \alpha$ and $8 \beta$ subunits with different combinations and ligand specificity (3). They link the ECM to the intracellular actin cytoskeleton and stimulate the intracellular signaling pathway that modulates proliferation, migration and invasion of cells. Compared with normal cells, metastatic tumor cells often overexpress certain integrins. For example, $\alpha_{\mathrm{V}} \beta_{3}, \alpha_{\mathrm{V}} \beta_{5}$ and $\alpha_{5} \beta_{1}$, a subfamily of integrins, have been demonstrated to be upregulated in lung, melanoma, breast and brain tumors, which make them ideal pharmacological targets for the development of antitumorigenic and antiangiogenic compounds (4,5). Recently, a tripeptide sequence Arg-Gly-Asp (RGD) which is a conserved motif present in ECM proteins, has been identified as an important tool in targeting drugs and imaging agents because of its high affinity to $\alpha_{\mathrm{V}} \beta_{3}, \alpha_{\mathrm{V}} \beta_{5}$ and $\alpha_{5} \beta_{1}$ integrins. Therefore, RGD has been investigated as an ideal promising ligand for the development of antitumor or antimetastatic agents.

Many natural peptides containing the RGD motif have been examined as effective agents with antitumor and antimetastatic activity (6). Lunasin is such a novel 43 -amino acid peptide originally isolated from soybean seed with the sequence: SKWQHQQDSCRKQLQGVNLTPCEKHIMEKI QGRGDDDDDDDDD (7). To date, lunasin and its analogues have been successively identified in barley (8), wheat (9) and other plants, e.g. Amaranth, a plant cultivated in Mexico (10), and a traditional Chinese herb, Solanum nigrum L. (11). There is accumulating evidence showing that the bioactivity of lunasin is highly associated with its unique peptide sequences consisting of three functional regions: a C-terminal tail with 8 aspartic acid residues (poly-D), helping lunasin bind directly to histones affecting the $\mathrm{H} 3$ and $\mathrm{H} 4$ acelylation/deacelylation 
process (12); a predicted and structurally conserved helix region targeting lunasin to the chromatin. Moreover, as a cell adhesion motif, RGD potentiates the ability of lunasin to internalize into cells and compete with ECM to interact with integrins, such as $\alpha_{\mathrm{V}} \beta_{3}, \alpha_{\mathrm{V}} \beta_{5}$ or $\alpha_{5} \beta_{1}$, which is crucial in angiogenesis, tumor progression and metastasis. It was found that lunasin inhibited cell proliferation and induced apoptosis in breast, colon and leukemia cancers owing to its RGD motif (13). As reported, lunasin inhibited the metastasis of colon cancer cells by direct binding with $\alpha_{5} \beta_{1}$ integrin through suppression of focal adhesion kinase (FAK)/ERK/NF- $\kappa \mathrm{B}$ signaling in vitro and in a mouse model (14). Lunasin has also been reported to exert anti-inflammatory effects on human macrophages via inhibition of the $\alpha_{V} \beta_{3}$ integrin-mediated Akt/NF- $\kappa$ B pathway (15). Additionally, when combined with other chemopreventive agents anacardic acid or oxaliplatin, lunasin potentiated their antitumor effects on MDA-MB-231 (16), and KM12L4 (14) cells, respectively, indicating that this peptide has a promising role as a co-adjuvant in cancer therapy.

Although research has proven that lunasin is an effective bioactive peptide in many cancer therapies, the effect and mechanism of lunasin in regards to the metastasis of breast cancer cells are largely unknown. In this study, we assessed the potential inhibitory effects of lunasin on the growth, migration, invasion and ECM degradation of breast cancer cells. We also verified that lunasin exerts its antimetastatic effect by decreasing the activity and expression of MMP-2/-9 and inactivating the associated proteins in the FAK/Akt/ERK and $\mathrm{NF}-\kappa \mathrm{B}$ pathways.

\section{Materials and methods}

Cell lines. Human breast cancer cell lines MCF-7 and MDA-MB-231 were purchased from the Institute of Biochemistry and Cell Biology, Chinese Academy of Sciences (Shanghai, China). MCF-7 cells were cultured in Dulbecco's modified Eagle's medium (DMEM; Gibco, Grand Island, NY, USA) supplemented with 10\% FBS (Biological Industries, Kibbutz Beit-Haemek, Israel), $100 \mathrm{mg} / \mathrm{ml}$ streptomycin and $100 \mathrm{U} / \mathrm{ml}$ penicillin in a $5 \% \mathrm{CO}_{2}$ atmosphere at $37^{\circ} \mathrm{C}$. MDA-MB-231 cells were cultured in L15 (Sigma-Aldrich, St. Louis, MO, USA) supplemented with $10 \% \mathrm{FBS}, 100 \mathrm{mg} / \mathrm{ml}$ streptomycin and $100 \mathrm{U} / \mathrm{ml}$ penicillin (Beyotime Institute of Biotechnology, Shanghai, China) at $37^{\circ} \mathrm{C}$.

Reagents. Lunasin, SKWQHQQDSCRKQLQGVNLTPCEK HIMEIGRDDDDDDDDD was synthesized by GL Biochem (Shanghai, China). The purity of the peptide was higher than $95 \%$. Stock solutions of synthetic lunasin $(1 \mathrm{mM})$ were prepared with sterile distilled water and stored at $-20^{\circ} \mathrm{C}$.

3-(4,5-Dimethylthiazol-2-yl)-2,5-diphenyltetrazolium bromide (MTT) and PMSF were obtained from SigmaAldrich. BCA protein assay kit, RIPA lysis buffer and nuclear/ cytoplasmic protein extraction kit were purchased from Beyotime Institute of Technology. The primary antibodies to phospho-Akt (Ser473) rabbit mAb, Akt rabbit mAb, phosphoSrc family (Tyr416) rabbit $\mathrm{mAb}$, Src rabbit mAb, phosphoFAK (Tyr397) rabbit mAb, FAK rabbit mAb, phospho-p44/42 MAPK (Erk1/2) (Thr202/Tyr204) rabbit mAb, p44/42 MAPK (Erk1/2) rabbit mAb, phospho-NF- $\mathrm{B}$ p65 (Ser536) rabbit
$\mathrm{mAb}, \mathrm{I} \kappa \mathrm{B} \alpha$ mouse mAb, phospho-I $\mathrm{B} \alpha$ (Ser32) rabbit mAb, $\mathrm{NF}-\kappa \mathrm{B}$ p65 rabbit $\mathrm{mAb}, \beta$-actin mouse $\mathrm{mAb}$, Lamin $\mathrm{B} 2$ (D8P3U) rabbit mAb, anti-rabbit IgG, HRP-linked antibody, anti-mouse IgG and HRP-linked antibody were all purchased from Cell Signaling Technology, Inc. (Danvers, MA, USA).

Cell viability assay. Cell viability was assessed using an MTT assay. MCF-7 and MDA-MB-231 cells were plated at a density of $1 \times 10^{4}$ cells/well in a 96-well plate overnight and then treated with various concentrations of lunasin peptide $(0-320 \mu \mathrm{M})$ for 24 or $48 \mathrm{~h}$. At the end of the treatment, $20 \mu \mathrm{l}$ of MTT $(5 \mathrm{mg} / \mathrm{ml})$ was added and incubated at $37^{\circ} \mathrm{C}$ for $4 \mathrm{~h}$. The supernatant was aspirated and the formazan crystals that formed were dissolved in $150 \mu \mathrm{l}$ DMSO for $20 \mathrm{~min}$. The absorbance at $490 \mathrm{~nm}$ was measured with a microplate reader (Spectra Max 190; Molecular Devices, LLC, Sunnyvale, CA, USA). The viability was expressed as the percentage of the lunasin-treated group to the control group, considered as $100 \%$. All data were analyzed from three independent experiments with six replicates and the results are expressed as the mean \pm SD.

Wound healing assay. The wound healing assay was performed as previously reported with some modifications (17). MCF-7 and MDA-MB-231 cells were seeded into a 6-well plate until growth to $70 \%$ confluence with complete medium. A plastic tip $(1 \mathrm{~mm})$ was used to make a scratch on the cell monolayer as previously described (18). Then the wound area was washed three times with PBS to remove cell debris and the cells were incubated with lunasin $(0-20 \mu \mathrm{M})$ for $24 \mathrm{~h}$. The cells were allowed to migrate into the wound surface and the average distance of the migrating cells was observed using inverted microscopy (Leica Microsystems GmbH, Wetzlar, Germany) at different times. The migration rate was expressed as the migrated distance of the cells in the experimental group to that of the control group. All data were analyzed from three independent experiments performed in triplicate and the results are expressed as the mean $\pm \mathrm{SD}$.

Invasion assay. The invasion assay was performed using a Transwell chamber ( $8 \mu \mathrm{m}$ pore polycarbonate, Corning Costar, Cambridge, MA, USA) coated with the diluted BD Matrigel ${ }^{\mathrm{TM}}$ basement membrane matrix (BD Biosciences, Bedford, MA, USA). MCF-7 and MDA-MB-231 cells treated with lunasin $(0-20 \mu \mathrm{M})$ for $24 \mathrm{~h}$ were trypsinized and suspended at a final concentration of $1 \times 10^{6}$ cells $/ \mathrm{ml}$ in serum-free DMEM and L15 medium, respectively. Cell suspension was added into each Transwell upper chamber of and the medium with 5\% FBS was applied to the bottom of the chamber as a chemoattractant. The chamber was incubated at $37^{\circ} \mathrm{C}$ for $24 \mathrm{~h}$. After incubation, the non-invaded cells in the upper chamber were removed from the Transwell membrane with a cotton swab. The invaded cells in the lower chamber were fixed with $100 \%$ methanol and then stained with $1 \%$ crystal violet in $2 \%$ ethanol. The invaded cells were counted and photographed under a microscope at five different fields of the chamber. The data are presented as the average number of invaded cells in the experimental group to the control group. All data were analyzed from three independent experiments performed in triplicate and the results are expressed as the mean $\pm \mathrm{SD}$. 


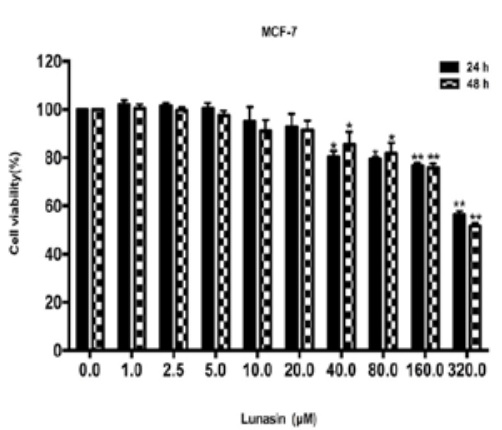

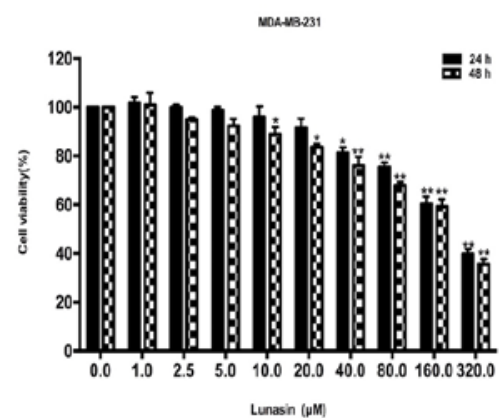

C

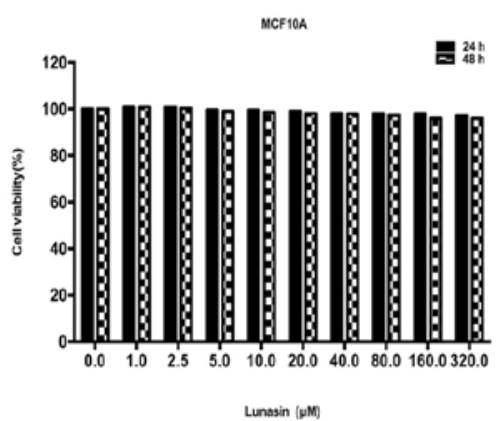

Figure 1. Cell viability of breast cancer cells following treatment with lunasin using MTT assay. (A) Cell viability of MCF-7 cells after treatment with lunasin for $24 \mathrm{~h}$ and $48 \mathrm{~h}$ at different concentrations $(0-320 \mu \mathrm{M})$. (B) Cell viability of MDA-MB-231 cells after treatment with lunasin for 24 and $48 \mathrm{~h}$ at different concentrations $(0-320 \mu \mathrm{M})$. (C) Cell viability of MCF10A cells after treatment with lunasin for 24 and $48 \mathrm{~h}$ at different concentrations $(0-320 \mu \mathrm{M})$. The value for each concentration tested represents the mean $\pm \mathrm{SD}$ of three independent experiments with six replicates. ${ }^{*} \mathrm{P}<0.05$ vs. the control, ${ }^{* *} \mathrm{P}<0.01 \mathrm{vs}$. the control.

Gelatin zymography. The proteolytic activity of MMP-2 and MMP-9 in the supernatant was analyzed by gelatin zymography assay as previously described (19). MCF-7 and MDA-MB-231 cells were treated with lunasin $(0-20 \mu \mathrm{M})$ in serum-free medium for $24 \mathrm{~h}$. After incubation, the supernatant of the cells was collected and centrifuged at $1,000 \mathrm{x} \mathrm{g}$ at $4^{\circ} \mathrm{C}$ for $10 \mathrm{~min}$. Samples were then loaded on $8 \%$ SDS-polyacrylamide gel containing $0.1 \%$ gelatin. The electrophoresis was performed at $100 \mathrm{~V}$. When finished, the gel was washed with elution buffer $\left(2.5 \%\right.$ Triton $\mathrm{X}-100,50 \mathrm{mM}$ Tris- $\mathrm{HCl}, 5 \mathrm{mM} \mathrm{CaCl}_{2}$ and $1 \mu \mathrm{M} \mathrm{ZnCl}$, pH 7.6) and washing buffer $(50 \mathrm{mM}$ Tris- $\mathrm{HCl}$, $5 \mathrm{mM} \mathrm{CaCl}_{2}$ and $1 \mu \mathrm{M} \mathrm{ZnCl}$, pH 7.6) twice, followed by reaction with incubation solution $(50 \mathrm{mM}$ Tris- $\mathrm{HCl}, 5 \mathrm{mM}$ $\mathrm{CaCl}_{2}, 1 \mu \mathrm{M} \mathrm{ZnCl}_{2}$ and $0.02 \%$ Brij-35, $\mathrm{pH} \mathrm{7.6)} \mathrm{for} 48 \mathrm{~h}$ at $37^{\circ} \mathrm{C}$. Finally, the gel was stained with staining buffer $(0.05 \%$ Coomassie Blue R-250, 30\% methanol and 10\% acetic acid) and destained with destaining buffer A (30\% methanol and $10 \%$ acetic acid), B (20\% methanol and $10 \%$ acetic acid) and $\mathrm{C}(10 \%$ methanol and $50 \%$ acetic acid) by turn. The results were photographed and analyzed by Biospectrum Imaging system (UVP, Inc., Upland, CA, USA) and Image J software. The data are presented as the degree of grey in the enzymatic region in the lunasin-treated group vs. the control group. All data were analyzed from three independent experiments performed in triplicate and the results are expressed as the mean $\pm \mathrm{SD}$.

Western blot analysis. MCF-7 and MDA-MB-231 cells were cultured in a 6 -well plate at a density of $2 \times 10^{5}$ cells/well. After incubation, the cells were pretreated with different concentrations of lunasin $(0-20 \mu \mathrm{M})$ for $24 \mathrm{~h}$. Then, the cells were harvested and lysed with the RIPA cell lysis buffer in the presence of a protease inhibitor PMSF. The samples were incubated for $30 \mathrm{~min}$ on ice and centrifuged at 8,000 $\mathrm{x}$ g for $15 \mathrm{~min}$ at $4^{\circ} \mathrm{C}$. The cell extracts were collected and stored at $-80^{\circ} \mathrm{C}$ until use in subsequent experiments. Total cellular and nuclear proteins were extracted according to the instructions of the nuclear and cytoplasmic protein extraction kit. The nuclear extracts were used to determine $\mathrm{NF}-\kappa \mathrm{B}$ protein levels and the cytoplasmic extracts were used to determine I $\kappa \mathrm{B}$ levels. The protein concentration was determined using the BCA protein assay kit. Equal amounts of protein were separated by sodium dodecyl sulfate-polyacrylamide gel electrophoresis (SDS-PAGE) and transferred to a polyvinylidene fluoride (PVDF) membrane. Western blot analysis was carried out as previously described (20). The protein bands were visualized by enhanced chemiluminescence detection reagents (Applygen Technologies Inc., Beijing, China) using a Biospectrum Imaging system.

Statistical analysis. All data are presented as the mean \pm standard deviation (SD) of 3 independent experiments performed in triplicate. Statistical analysis was performed by Student's t-test or one-way analysis of variance (ANOVA). In all cases, $\mathrm{P}<0.05$ was considered statistically significant, $\mathrm{P}<0.01$ was considered extremely significant.

\section{Results}

Cytotoxic effect of lunasin on MCF-7 and MDA-MB-231 breast cancer cells. To evaluate the cytotoxic effect of lunasin on human breast cancer MCF-7 and MDA-MB-231 cells, the viability was determined by MTT assay. As shown in Fig. 1A and B, lunasin did not exhibit strong cytotoxic effects on MCF-7 and MDA-MB-231 cells until the concentration reached $20 \mu \mathrm{M}$. With the increase in lunasin concentration and incubation time, the viability of the cells was markedly decreased, which demonstrated that lunasin may exert its inhibitory effect in concentration- and time-dependent manners. After treatment with lunasin for 24 and $48 \mathrm{~h}$, the $\mathrm{IC}_{50}$ values in the MCF-7 cells were $508.6 \mu \mathrm{M}$ and $431.9 \mu \mathrm{M}$, respectively. The cell viability of the MDA-MB-231 cells following treatment with lunasin (Fig. 1B) was much lower than that of the MCF-7 cells. The $\mathrm{IC}_{50}$ was $224.7 \mu \mathrm{M}$ at $24 \mathrm{~h}$ and $194.9 \mu \mathrm{M}$ at $48 \mathrm{~h}$. The cytotoxic effect of lunasin was also investigated in human normal breast MCF-10A cells (Fig. 1C). As previosly reported (21), lunasin selectively kills cancer cells without having an effect on normal cells.

\section{Lunasin inhibits the migration and motility of breast cancer} cells in vitro. A scratch wound assay was carried out to evaluate the migration and motility of the breast cancer cells following treatment with lunasin. According to the MTT assay results, 0-20 $\mu \mathrm{M}$ lunasin was selected for its 
A

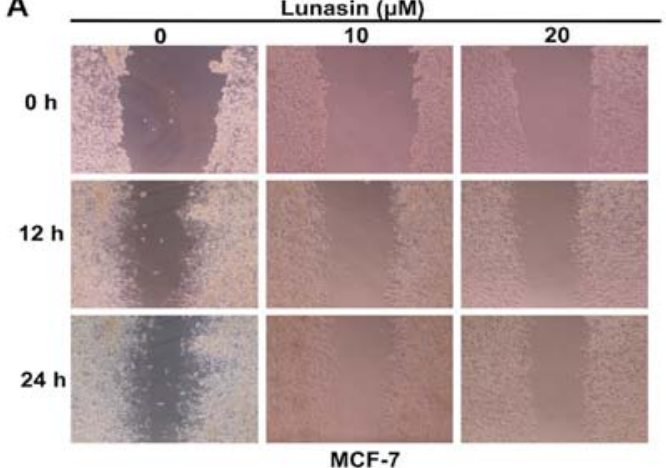

C

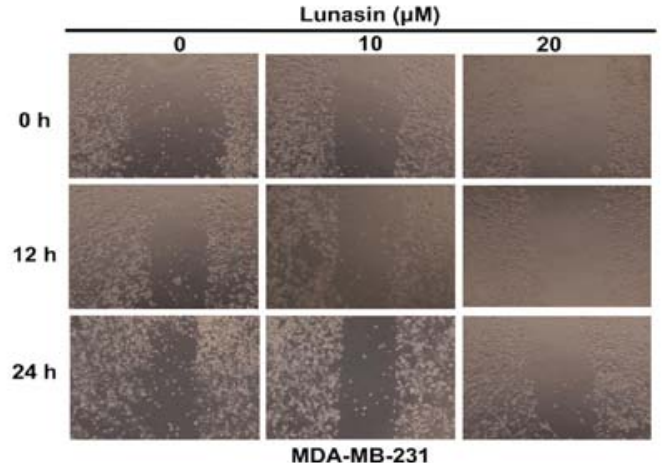

B

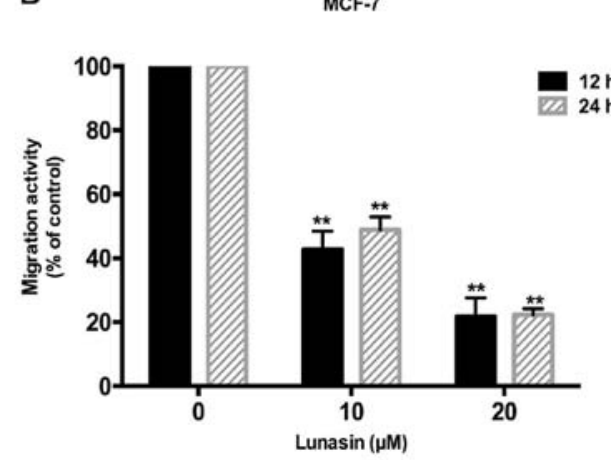

D

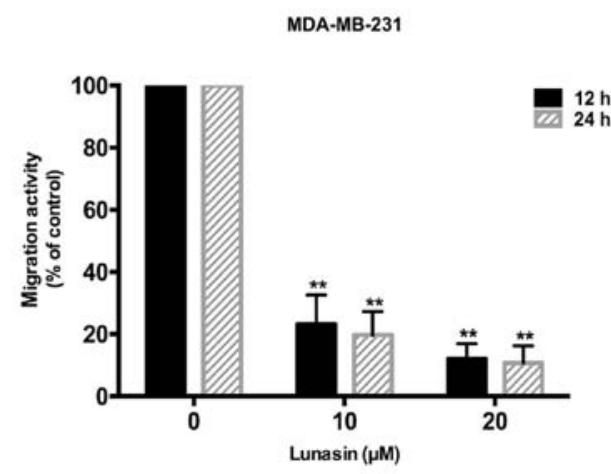

Figure 2. Inhibitory effect of lunasin on breast cancer migration and motility. (A) The scratch wound assay following treatment with lunasin (0-20 $\mu \mathrm{M})$ in MCF-7 breast cancer cells for $24 \mathrm{~h}$. Representative images show the wound-induced motility of MCF-7 cells. The images were captured three times at different areas and the results were analyzed by Image $\mathbf{J}$ software. (B) The migration rate of MCF-7 cells treated with lunasin $(0-20 \mu \mathrm{M})$. (C) The scratch wound assay in MDA-MB-231 breast cancer cells following treatment with lunasin $(0-20 \mu \mathrm{M})$ in $24 \mathrm{~h}$. (D) The migration rate of MDA-MB-231 treated by lunasin $(0-20 \mu \mathrm{M})$. The data are represented as the mean $\pm \mathrm{SD}$ of three independent experiments in triplicate. The histograms $(\mathrm{B}$ and $\mathrm{D})$ show the migration rate as determined by the ratio of migrated wound width in the lunasin-treated group to the control group. ${ }^{*} \mathrm{P}<0.05$ vs. the control. ${ }^{* *} \mathrm{P}<0.01$ vs. the control.

A

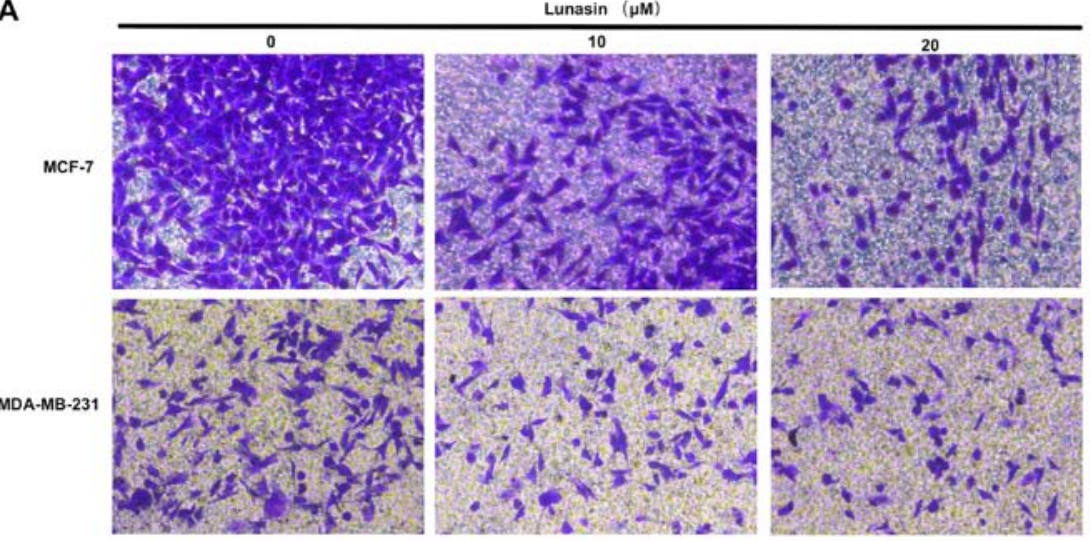

B

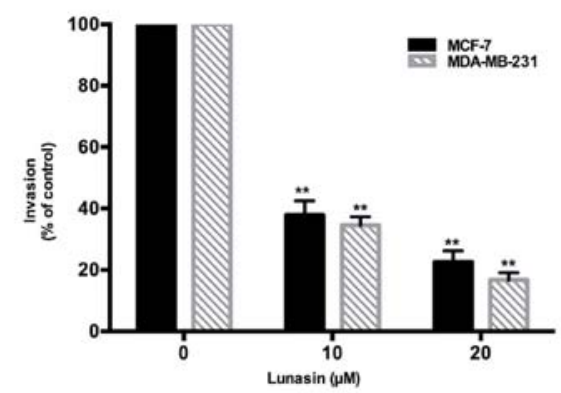

Figure 3. Inhibitory effect of lunasin on breast cancer invasion. (A) The effect of lunasin (0-20 $\mu \mathrm{M})$ on the invasion of MCF-7 and MDA-MB-231 breast cancer cells. Representative images show the invaded cells stained with crystal violet. The images were captured three times at different areas and the results were analyzed by Image J software. (B) The invasion rate of MCF-7 and MDA-MB-231 cells treated with lunasin (0-20 $\mu \mathrm{M})$ for $24 \mathrm{~h}$. The invasion rate was determined by the number of invaded cells in the lunasin-treated group to the control group. The data are represented as the mean \pm SD of three independant experiments in triplicate. ${ }^{*} \mathrm{P}<0.05$ vs. the control. ${ }^{* *} \mathrm{P}<0.01$ vs. the control. 

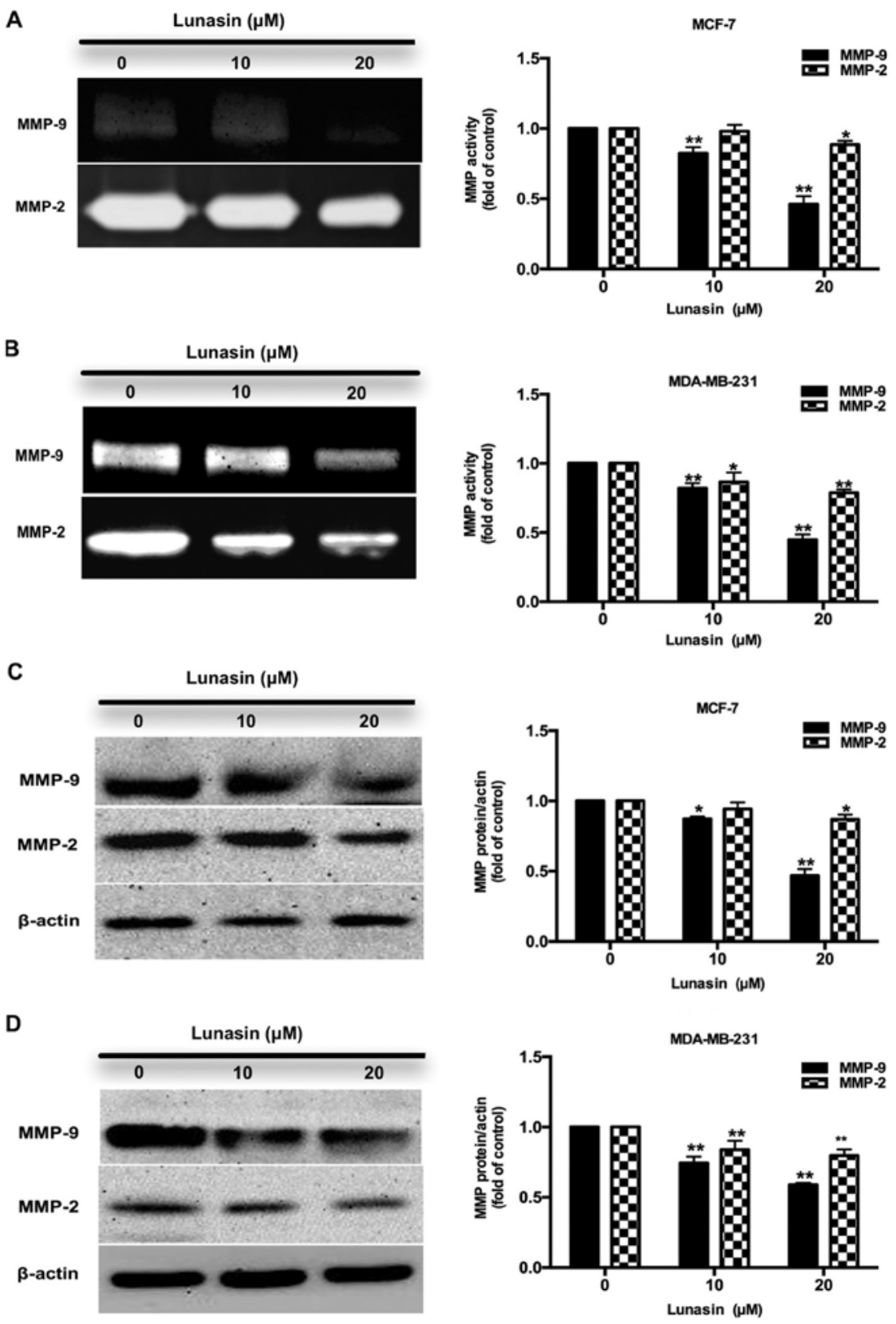

Figure 4. Effect of lunasin on the activity and expression of MMP-2 and MMP-9 in breast cancer cells. (A) The inhibitory effect of lunasin ( $0-20 \mu \mathrm{M})$ on the activity of MMP-2 and MMP-9 in (A) MCF-7 and (B) MDA-MB-231 cells as assessed by gelatin zymography. The histograms represent the quantification of MMP activity in the MCF-7 and MDA-MB-231-7 cells following treatment with lunasin (0-20 $\mu \mathrm{M})$ compared to the control. (C) The inhibitory effect of lunasin $(0-20 \mu \mathrm{M})$ on the expression of MMP-2 and MMP-9 in (C) MCF-7 and (D) MDA-MB-231 cells as assessed by western blot analysis. Corresponding histograms represent the relative expression quantity of the target protein to the control analyzed by Image J software. The data are represented as the mean \pm SD of three independent experiments in triplicate. ${ }^{*} \mathrm{P}<0.05$ vs. the control. ${ }^{* *} \mathrm{P}<0.01$ vs. the control.

non-cytotoxicity to cells. As shown in Fig. 2A and B, lunasin effectively inhibited the migration of MCF-7 cells after a 24-h treatment. Compared with the control group, the migration rate in the lunasin group decreased gradually with an increase in lunasin concentration. The same phenomenon was also observed in the MDA-MB-231 cells following treatment with lunasin (Fig. 2C and D). All the results indicated that lunasin significantly suppressed the migration of MCF-7 and MDA-MB-231 breast cancer cells in a dose-dependent manner.

Lunasin inhibits the invasion of breast cancer cells. The inhibitory effects of lunasin on the invasion of breast cancer cells were investigated by Transwell invasion assay. Fig. 3 shows that after incubation for $24 \mathrm{~h}$, lunasin $(10-20 \mu \mathrm{M})$ markedly decreased the number of invasive cells in both the MCF-7 and MDA-MB-231 cells. The invasiveness of the MCF-7 and MDA-MB-231 cells became less aggressive with an increase in lunasin concentration. These findings were consistent with the wound scratch assay, which indicated that lunasin suppresses the metastasis of breast cancer cells.

Lunasin reduces the activity and expression of $M M P-2 /-9$ in breast cancer cells. Matrix metalloproteinases (MMPs) are a family of proteins that can degrade the ECM leading to tumor metastasis, apoptosis and carcinogensis (22). Among the MMP 
A
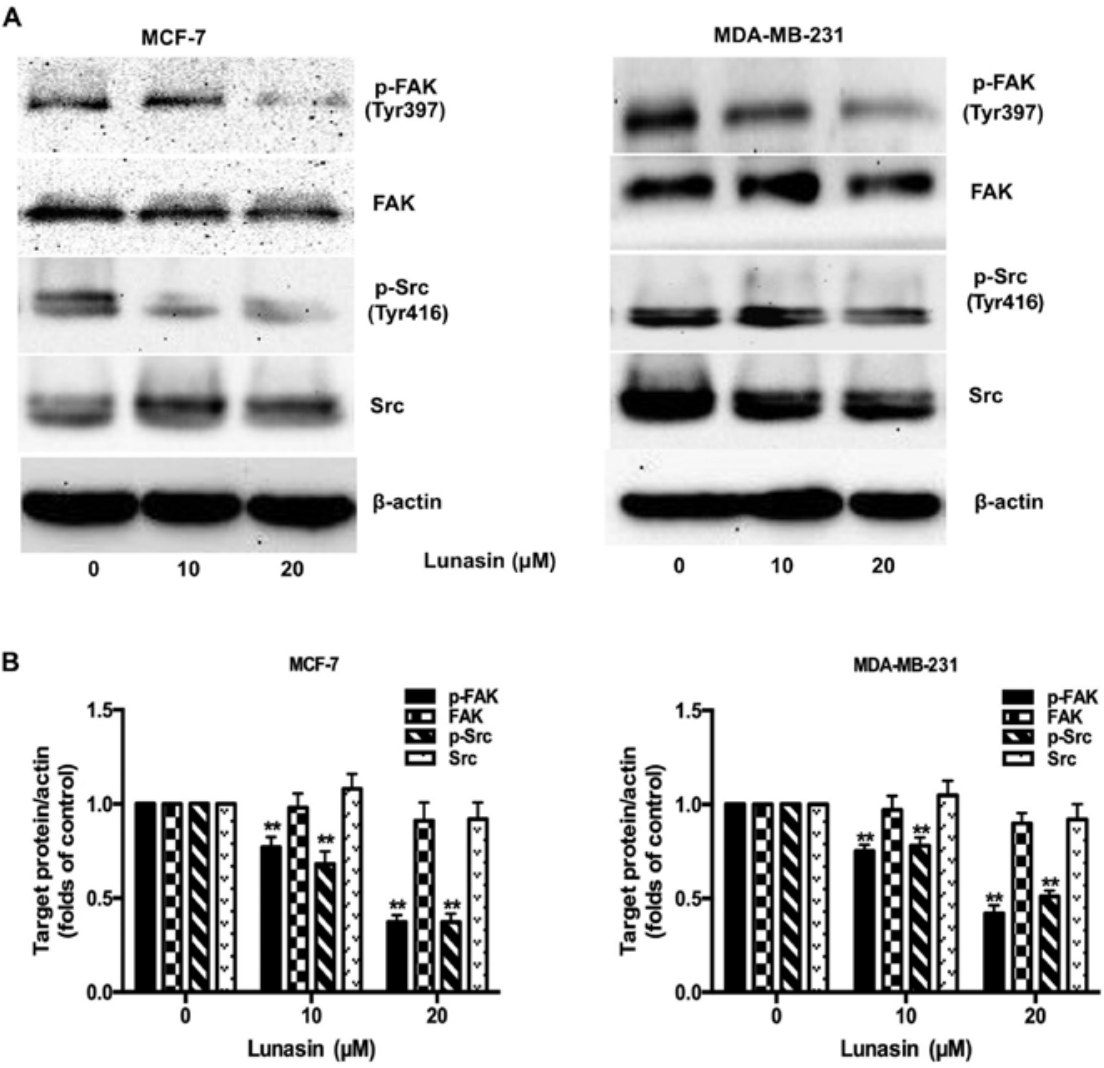

Figure 5. Effects of lunasin on the expression and phosphorylation of focal adhesion kinase (FAK) and Src in breast cancer cells. (A) The effects of lunasin on the expression levels of phosphorylated and total FAK and Src in the MCF-7 and MDA-MB-231 breast cancer cells. (B) The corresponding histograms represent the relative expression quantity of the target protein to the control as analyzed by Image $\mathbf{J}$ software. The data are represented as the mean \pm SD of three independant experiments. ${ }^{*} \mathrm{P}<0.05$ vs. the control. ${ }^{* *} \mathrm{P}<0.01$ vs. the control.
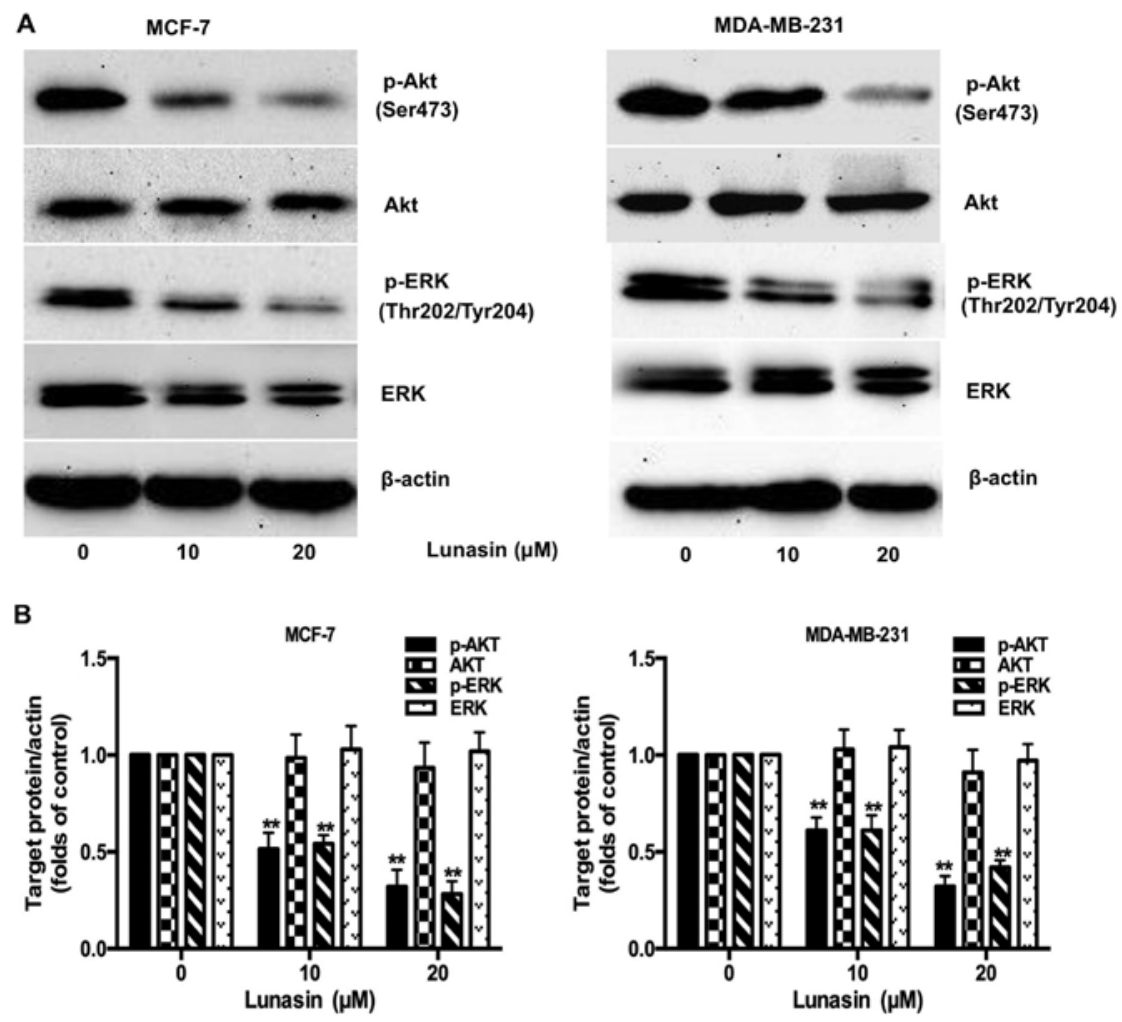

Figure 6. Effect of lunasin on the expression and phosphorylation of Akt and ERK in breast cancer cells. (A) The inhibitory effects on the expression levels of phosphorylated and total Akt and ERK in the MCF-7 and MDA-MB-231 breast cancer cells as analyzed by western blotting. (B) Corresponding histograms represent the relative expression quantity of the target protein to the control analyzed by Image J software. The data are represented as the mean \pm SD of three independent experiments. ${ }^{*} \mathrm{P}<0.05$ vs. the control. ${ }^{* *} \mathrm{P}<0.01$ vs. the control. 
A

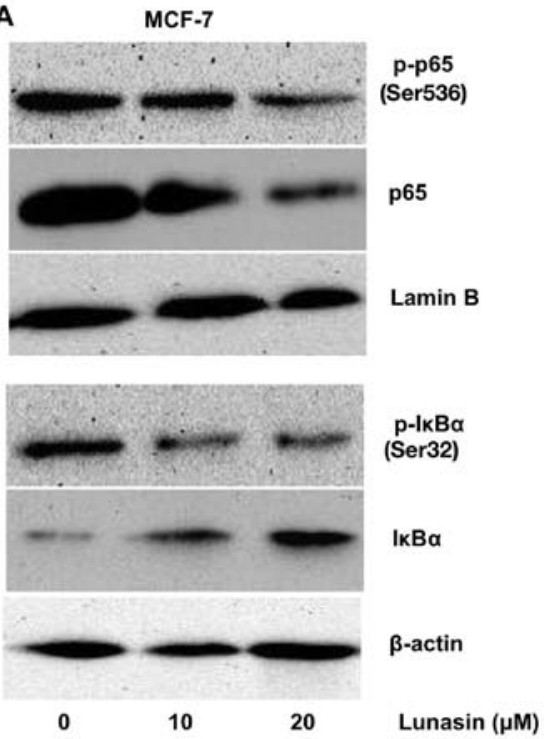

B

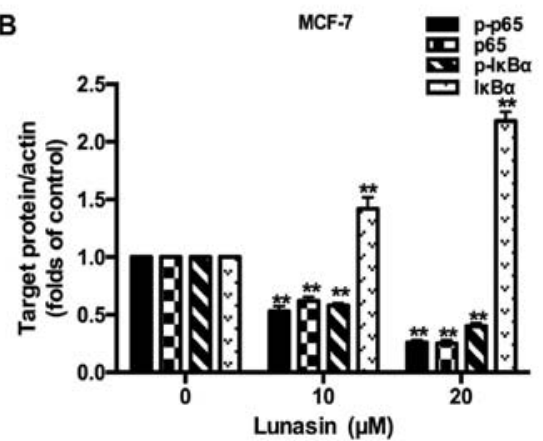

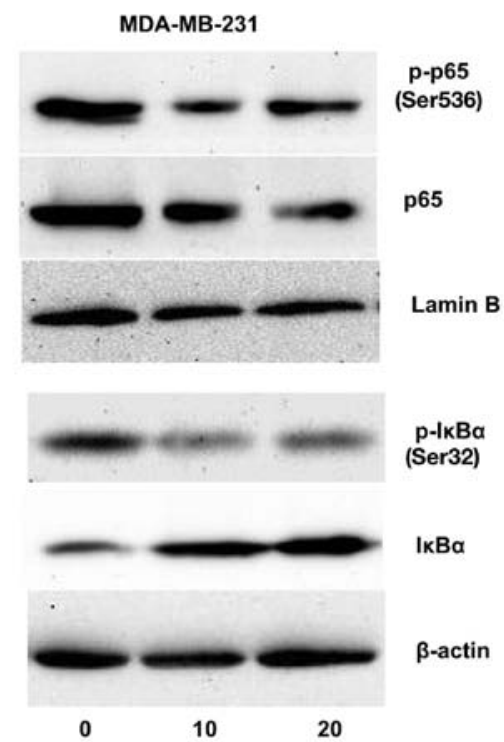

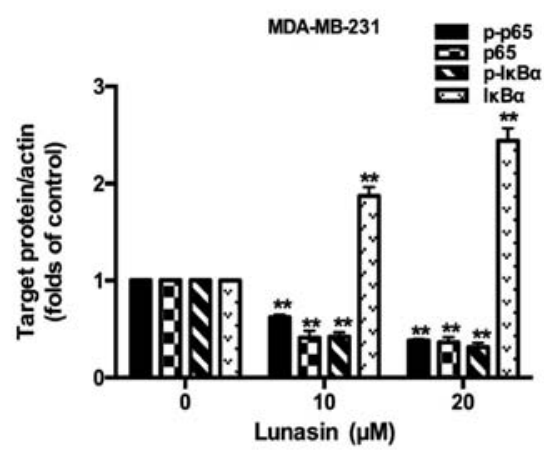

Figure 7. Effect of lunasin on the expression and phosphorylation of $\mathrm{I \kappa B} \alpha$ and $\mathrm{p} 65$ in breast cancer cells. (A) The effects of lunasin on the expression levels of phosphorylated and total IкB $\alpha$ in the cytoplasm and p65 in the nucleus of MCF-7 and MDA-MB-231 breast cancer cells as analyzed by western blot analysis. (B) Corresponding histograms represent the relative expression quantity of the target protein to the control analyzed by Image J software. The data are represented as the mean $\pm \mathrm{SD}$ of three independent experiments. ${ }^{*} \mathrm{P}<0.05$ vs. the control. ${ }^{* *} \mathrm{P}<0.01$ vs. the control.

proteins, MMP-2 and MMP-9 are highly expressed and correlated with the metastasis of breast tumors (23). Hence, in this study the activity and expression of MMP-2 and MMP-9 were investigated by gelatin zymography and western blot analysis to examine the possible anti-invasive ability of lunasin. As shown in Fig. 4A and B, lunasin (10-20 $\mu \mathrm{M})$ reduced the activity and expression of MMP-9 in the MCF-7 cells. However, there were no significant changes in the activity and expression of MMP-2. In the MDA-MB-231 cells (Fig. 4C and D), lunasin sharply reduced the activity and expression of MMP-9 and decreased that of MMP-2 gradually. The differences in MMP-2 expression may be attributed to the different characteristics between the two breast cancer cell lines.

Lunasin suppresses the phosphorylation of FAK and Src. FAK, a cytoplasmic protein tyrosine kinase, is crucial for proliferation, migration, adhesion and invasion of cancer cells (24). It has been reported that FAK is activated by integrinclustering and autophosphorylated at Tyr397 (25). Once phosphorylated, FAK supplies a binding site for Src to form the FAK-Src complex, which recruits more signaling molecules participating in integrin-mediated signaling transduction (26). Therefore, we assessed the expression of phosphorylated FAK and Src in breast cancer cells after treatment with lunasin for
24 h. As shown in Fig. 5A and B, lunasin strongly inhibited the phosphorylation of FAK and Src in both MCF-7 and MDA-MB-231 cell lines. It did not have significant effects on total FAK and Src, which demonstrated that lunasin exerted its antimetastatic effect by preventing the phosphorylation of FAK and Src from forming the FAK-Src complex.

Lunasin suppresses the phosphorylation of ERK and Akt. Studies have found that the Ras/MEK/ERK and the PI3K/Akt pathways, the downstream signaling molecules activated by the FAK-Src complex, are correlated to the survival and metastasis of cancer cells (27). Hence, the phosphorylation of key molecules in these pathways, Akt and ERK, were examined further by western blot analysis. As shown in Fig. 6, the phosphorylation of Akt and ERK was attenuated by lunasin $(10-20 \mu \mathrm{M})$ in a concentration-dependent manner. There were no significant differences in the total amount of Akt and ERK. The results illustrated that lunasin may inhibit the metastasis of breast cancer cells by blocking the PI3K/Akt/ERK pathway.

Lunasin inactivates the translocation process of $N F-\kappa B$ into the nucleus. $\mathrm{NF}-\kappa \mathrm{B}$, an important transcriptional factor, regulates the expression of many genes involved in mammary carcinogenesis, survival and metastasis of breast cancer 
cells (28). The activation of NF- $\mathrm{BB}$ is controlled by the targeted phosphorylation and subsequent degradation of $\mathrm{I} \kappa \mathrm{B}$, which prevents NF- $\kappa \mathrm{B}$ from translocation into the nucleus. To further explore the underlying mechanisms of lunasin, the expression of the NF- $\kappa \mathrm{B}$ inhibitor, I $\kappa \mathrm{B} \alpha$ and $\mathrm{p}-\mathrm{I} \kappa \mathrm{B} \alpha$ in the cytoplasm, the translocation of NF- $\kappa \mathrm{B}, \mathrm{p} 65$ and p-p65 in the nucleus, were all examined in our study using western blot analysis. The results showed that the phosphorylation and degradation of $\mathrm{I} \kappa \mathrm{B} \alpha$ were markedly inhibited by lunasin $(10-20 \mu \mathrm{M})$ with enhanced I $\mathrm{B}$ expression (Fig. 7). Accordingly, the translocation of activated $\mathrm{NF}-\kappa \mathrm{B}, \mathrm{p}-\mathrm{p} 65$ and p65 in the nucleus, was decreased following treatment with lunasin.

\section{Discussion}

Metastasis is a series of complex processes consisting of cancer cell proliferation, cell motility, cell adhesion to ECM and ECM proteolysis. It has been reported that $90 \%$ of breast cancer deaths are attributed to the metastasis of cancer cells. Therefore, it is urgent to develop new therapeutic agents to inhibit the metastasis of breast cancer. Lunasin, a 43-amino acid peptide derived from soybeans, is a bioactive peptide which has been demonstrated as an effective chemopreventive and antitumor agent in cancer therapy. However, knowledge of the inhibitory effects of lunasin on the metastasis of breast cancer cells and its underlying mechanism is limited. In this study, we demonstrated that lunasin suppressed the proliferation, migration and invasion of breast cancer cells. Meanwhile, the activity and expression of MMP-2/-9, phosphorylation of FAK, Src, Akt, ERK, p65, I $\kappa \mathrm{B} \alpha$ and translocation of p 65 were decreased, which indicated that lunasin inhibited the metastasis of breast cancer cells via suppression of the FAK/Akt/ERK and $\mathrm{NF}-\kappa \mathrm{B}$ pathways.

In this present study, we found that lunasin suppressed the proliferation of MCF-7 and MDA-MB-231 breast cancer cells with $\mathrm{IC}_{50}$ values of $508.6 \mu \mathrm{M}$ and $224.7 \mu \mathrm{M}$, respectively. These values were slightly higher than those of previous research (29), in which the $\mathrm{IC}_{50}$ value of MDA-MB-231 was $181 \mu \mathrm{M}$ following treatment by synthetic lunasin. In order to examine the antimetastatic potential of the peptide, $10-20 \mu \mathrm{M}$ lunasin was selected because of its non-cytotoxicity to MCF-7 and MDA-MB-231 breast cancer cells. Migration and invasion are two critical processes during the metastasis of cancer cells. The migratory and invasive abilities of cancer cells enable them to migrate to adjacent tissues finally leading to metastasis. In the present study, the inhibitory effects of lunasin on migration and invasion were observed by scratch wound and Transwell assays. As shown in Figs. 2 and 3, lunasin was able to effectively block the migration and invasion of MCF-7 and MDA-MB-231 cells in a concentration-dependent manner. Furthermore, as we examined, lunasin also inhibited the proteolytic degradation of the ECM. MMPs, a family of zinc-containing endopeptidases that can degrade the ECM, play a vital role in this process (30). Among the MMPs, MMP-2 and MMP-9 have been reported as being highly expressed in aggressive breast tumors and associated with poor prognosis $(31,32)$. In our study, it was found that lunasin strongly inhibited the activity and expression of MMP-9 in both the MCF-7 and MDA-MB-231 cell lines. Nevertheless, the decrease in MMP-2 was much more slight compared with MMP-9 in the MCF-7 and MDA-MB-231 cell lines. The results demonstrated that lunasin plays a more important role in the suppression of MMP-9 rather than MMP-2. In conclusion, the results substantiated the inhibitory ability of lunasin on the proliferation, migration, invasion and ECM degradation, which indicates that lunasin inhibits the metastasis of breast cancer cells.

Integrins, a family of heterodimer transmembrane glycoproteins, consist of $18 \alpha$ and $8 \beta$ subunits to form 24 different subtypes (33). In breast cancer cells, $\alpha_{v} \beta_{3}, \alpha_{v} \beta_{5}$ and $\alpha_{5} \beta_{1}$ integrins are often highly expressed in comparison to other subtypes, which can bind to ECM proteins such as fibronectin, vitronectin and collagen through a tripeptide motif Arg-Gly-Asp (RGD) to facilitate cell adhesion, migration, invasion and intracellular signaling (34). Hence, peptides containing the RGD motif are considered to be ideal agents to compete with ECM to interact specifically with integrins (35). Previous studies suggest that lunasin possesses an affinity for $\alpha_{\mathrm{v}} \beta_{3}$ and $\alpha_{5} \beta_{1}$ in macrophages (15) and cancer cells (36-38) which enable it to prevent the activation of the integrin-mediated signaling pathway by direct blockade. In this present study, we selected two typical breast cancer cell lines, ER-positive MCF-7 cells and ER-negative MDA-MB-231 cells with expression of different integrin subtypes. Research has confirmed that in MDA-MB-231 cancer cells, $\alpha_{\mathrm{v}} \beta_{3}$ is often highly expressed (39-41), while MCF-7 cells are $\alpha_{v} \beta_{3}$ negative but with $\alpha_{\mathrm{v}} \beta_{5}$ and $\alpha_{5} \beta_{1}$ expression (42). Thus, we examined the inhibitory effect on these two breast cancer cells and aimed to ascertain the underlying mechanism involved. The differences in the inhibitory effects of lunasin on these two cell lines may be ascribed to the different integrins and ER expression on their surface.

FAK, a receptor protein-tyrosine kinase, plays a central role in the intracellular signaling of integrin. Once integrin binds to the ECM, FAK is recruited to the clustering integrins and activated by autophosphorylation. Then Src is further phosphorylated to form the FAK-Src complex, which initiates the signal transduction of cell survival, proliferation, migration and invasion. As examined in our study (Fig. 5), lunasin strongly inhibited the phosphorylation of FAK and Src in both MCF-7 and MDA-MB-231 cell lines with no changes in total FAK and Src proteins. The results were consistent with the study conducted by Dia et al (14) in which it was reported, that lunasin suppresses the metastasis of colon cancer cells through inhibition of the FAK/Src pathway.

Previous studies have shown that decreased levels of MMP-9 and MMP-2, in breast cancer cells, are highly related to the inhibition of PI3K/Akt and ERK, both of which are downstream targets of FAK $(43,44)$. PI3K, a lipid kinase, participates in multiple cell signaling pathways through the activation of Akt. Additionally, activated Akt can lead to the invasion and metastasis of cancer cells by stimulating the secretion of MMPs $(45,46)$. It is accepted that the MAP family kinases possibly take part in signaling processes that modulate MMPs, including MMP-9 (47). In order to gain a better understanding of the mechanism by which lunasin inhibits tumor metastasis, the expression of Akt and ERK was examined by western blotting (Fig. 6). The results confirmed that lunasin markedly blocked the phosphorylation of Akt and ERK which may stop the cellular signaling to transcription factors of MMPs. 
Moreover, NF- $\mathrm{kB}$ is considered to regulate the survival, proliferation, chemoresistance, angiogenesis, cellular invasion and migration of cancer cells. Previous studies have reported that NF- $\mathrm{\kappa B}$ may be the transcriptional regulatory factor of MMPs and other genes, while I $\kappa B$ is an inhibitor which prevents NF- $\mathrm{KB}$ translocation into the nucleus (48). It was reported that PI3K activates IкB kinases (IKKs) to phosphorylate I $\mathrm{K} \mathrm{B}$, leading to its ubiquitination and proteasomal degradation to release the NF- $\mathrm{KB} /$ Rel complex. Lunasin has been shown to suppress the FAK/ERK/NF- $\kappa B$ signaling pathway in colon cancer cells (14) and Akt/NF- $\mathrm{KB}$ pathway in macrophages during activation of lipopolysaccharideinduced inflammation (49). In our study, we also found that lunasin inhibited the metastasis of breast cancer cells through preventing I $\mathrm{B}$ phosphorylated and enhancing I $\mathrm{K}$ protein expression, which decreased the phosphorylation and translocation of NF- $\kappa \mathrm{B}$.

In summary, lunasin inhibited the cell proliferation, cell migration, cell invasion and the activity and expression of MMP-2 and MMP-9 in breast cancer cells. We proposed that lunasin possibly exerted its inhibitory effect via the suppression of the integrin-mediated FAK/Akt/ERK and NF- $\mathrm{KB}$ signaling pathways. These results provide a foundation for future investigation of lunasin as an effective antitumor and antimetastatic agent for breast cancer therapy.

\section{Acknowledgements}

This study was supported by the National Natural Science Foundation of China (nos. 8147929 and 81573539), the Natural Science Foundation of Heilongjiang Province (no. H2015042), the Excellent Creative Talents Support Project of Heilongjiang University of Chinese Medicine (no. 2012RCQ12), the Research Foundation of Heilongjiang University of Chinese Medicine (no. 201004), and the Natural Science Foundation of Heilongjiang Province (no. H2015042).

\section{References}

1. Jemal A, Bray F, Center MM, Ferlay J, Ward E and Forman D: Global cancer statistics. CA Cancer J Clin 61: 69-90, 2011.

2. Weigelt B, Peterse JL and van't Veer LJ: Breast cancer metastasis: Markers and models. Nat Rev Cancer 5: 591-602, 2005.

3. Danen EH: Integrins: regulators of tissue function and cancer progression. Curr Pharm Des 11: 881-891, 2005.

4. Eliceiri BP and Cheresh DA: Adhesion events in angiogenesis. Curr Opin Cell Biol 13: 563-568, 2001.

5. Ruoslahti E: Specialization of tumour vasculature. Nat Rev Cancer 2: 83-90, 2002.

6. Temming K, Schiffelers RM, Molema G and Kok RJ: RGD-based strategies for selective delivery of therapeutics and imaging agents to the tumour vasculature. Drug Resist Updat 8: 381-402, 2005.

7. Galvez AF and de Lumen BO: A soybean cDNA encoding a chromatin-binding peptide inhibits mitosis of mammalian cells Nat Biotechnol 17: 495-500, 1999.

8. Jeong HJ, Lam Y and de Lumen BO: Barley lunasin suppresses ras-induced colony formation and inhibits core histone acetylation in mammalian cells. J Agric Food Chem 50: 5903-5908, 2002.

9. Jeong HJ, Jeong JB, Kim DS, Park JH, Lee JB, Kweon DH, Chung GY, Seo EW and de Lumen BO: The cancer preventive peptide lunasin from wheat inhibits core histone acetylation. Cancer Lett 255: 42-48, 2007.

10. Silva-Sánchez C, de la Rosa AP, León-Galván MF, de Lumen BO, de León-Rodríguez A and de Mejía EG: Bioactive peptides in amaranth (Amaranthus hypochondriacus) seed. J Agric Food Chem 56: 1233-1240, 2008.
11. Jeong JB, Jeong HJ, Park JH, Lee SH, Lee JR, Lee HK, Chung GY, Choi JD and de Lumen BO: Cancer-preventive peptide lunasin from Solanum nigrum L. inhibits acetylation of core histones H3 and $\mathrm{H} 4$ and phosphorylation of retinoblastoma protein (Rb). J Agric Food Chem 55: 10707-10713, 2007.

12. Hernández-Ledesma B,Hsieh CC and de Lumen BO: Relationship between lunasin's sequence and its inhibitory activity of histones H3 and H4 acetylation. Mol Nutr Food Res 55: 989-998, 2011.

13. de Lumen BO: Lunasin: a cancer-preventive soy peptide. Nutr Rev 63: 16-21, 2005

14. Dia VP and Gonzalez de Mejia E: Lunasin potentiates the effect of oxaliplatin preventing outgrowth of colon cancer metastasis, binds to $\alpha_{5} \beta_{1}$ integrin and suppresses FAK/ERK/NF- $\kappa \mathrm{B}$ signaling. Cancer Lett 313: 167-180, 2011.

15. Cam A and de Mejia EG: RGD-peptide lunasin inhibits Akt-mediated NF- $\kappa \mathrm{B}$ activation in human macrophages through interaction with the $\alpha_{\mathrm{V}} \beta_{3}$ integrin. Mol Nutr Food Res 56: 1569-1581, 2012.

16. Hsieh CC, Hernandez-Ledesma B and de Lumen B: Cell proliferation inhibitory and apoptosis-inducing properties of anacardic acid and lunasin in human breast cancer MDA-MB-231 cells. Food Chem 125: 630-636, 2011.

17. Liang CC, Park AY and Guan JL: In vitro scratch assay: a convenient and inexpensive method for analysis of cell migration in vitro. Nat Protoc 2: 329-333, 2007.

18. Xu Land Deng X: Protein kinase Ciota promotes nicotine-induced migration and invasion of cancer cells via phosphorylation of micro- and m-calpains. J Biol Chem 281: 4457-4466, 2006.

19. Li C, Zhao Y, Yang D, Yu Y, Guo H, Zhao Z, Zhang B and Yin X: Inhibitory effects of kaempferol on the invasion of human breast carcinoma cells by downregulating the expression and activity of matrix metalloproteinase-9. Biochem Cell Biol 93: 16-27, 2015.

20. Zhou R, Xu L, Ye M, Liao M, Du H and Chen H: Formononetin inhibits migration and invasion of MDA-MB-231 and 4T1 breast cancer cells by suppressing MMP-2 and MMP-9 through PI3K/AKT signaling pathways. Horm Metab Res 46: 753-760, 2014.

21. Hernández-Ledesma B, Hsieh CC and de Lumen BO: Lunasin, a novel seed peptide for cancer prevention. Peptides 30: 426-430, 2009.

22. McCawley LJ and Matrisian LM: Matrix metalloproteinases: multifunctional contributors to tumor progression. Mol Med Today 6: 149-156, 2000.

23. Hanemaaijer R, Verheijen JH, Maguire TM, Visser $H$, Toet K, McDermott E, O'Higgins N and Duffy MJ: Increased gelatinase-A and gelatinase-B activities in malignant vs. benign breast tumors. Int J Cancer. 86: 204-207, 2000.

24. Zhang J and Hochwald SN: The role of FAK in tumor metabolism and therapy. Pharmacol Ther 142: 154-163, 2014.

25. Toutant M, Costa A, Studler JM, Kadaré G, Carnaud M and Girault JA: Alternative splicing controls the mechanisms of FAK autophosphorylation. Mol Cell Biol 22: 7731-7743, 2002.

26. Schlaepfer DD, Mitra SK and Ilic D: Control of motile and invasive cell phenotypes by focal adhesion kinase. Biochim Biophys Acta 1692: 77-102, 2004.

27. van Nimwegen MJ and van de Water B: Focal adhesion kinase: a potential target in cancer therapy. Biochem Pharmacol 73: 597-609, 2007.

28. Wu JT and Kral JG: The NF-kappaB/IkappaB signaling system: a molecular target in breast cancer therapy. J Surg Res 123: 158-169, 2005.

29. Hsieh CC, Hernández-Ledesma B and de Lumen BO: Lunasin, a novel seed peptide, sensitizes human breast cancer MDA-MB-231 cells to aspirin-arrested cell cycle and induced apoptosis. Chem Biol Interact 186: 127-134, 2010.

30. Deryugina EI and Quigley JP: Matrix metalloproteinases and tumor metastasis. Cancer Metastasis Rev 25: 9-34, 2006.

31. Pellikainen JM, Ropponen KM, Kataja VV, Kellokoski JK, Eskelinen MJ and Kosma VM: Expression of matrix metalloproteinase (MMP)-2 and MMP-9 in breast cancer with a special reference to activator protein-2, HER2, and prognosis. Clin Cancer Res 10: 7621-7628, 2004.

32. Jezierska A and Motyl T: Matrix metalloproteinase-2 involvement in breast cancer progression: a mini-review. Med Sci Monit 15: RA32-40, 2009.

33. Takada Y, Ye X and Simon S: The integrins. Genome Biol 8: 215, 2007. 
34. Cabodi S, Di Stefano P, Leal MP, Tinnirello A, Bisaro B, Morello V, Damiano L, Aramu S, Repetto D, Tornillo G, et al: Integrins and signal transduction. Adv Exp Med Biol 674: 43-54, 2010.

35. Meyer A, Auernheimer J, Modlinger A and Kessler H: Targeting RGD recognizing integrins: drug development, biomaterial research, tumor imaging and targeting. Curr Pharm Des 12: 2723-2747, 2006.

36. Dia VP and Gonzalez de Mejia E: Lunasin induces apoptosis and modifies the expression of genes associated with extracellular matrix and cell adhesion in human metastatic colon cancer cells. Mol Nutr Food Res 55: 623-634, 2011.

37. de Mejia EG, Wang W and Dia VP: Lunasin, with an arginine-glycine-aspartic acid motif, causes apoptosis to L1210 leukemia cells by activation of caspase-3. Mol Nutr Food Res 54: 406-414, 2010

38. Inaba J, McConnell EJ and Davis KR: Lunasin sensitivity in non-small cell lung cancer cells is linked to suppression of integrin signaling and changes in histone acetylation. Int J Mol Sci 15: 23705-23724, 2014.

39. Meyer T, Marshall JF and Hart IR: Expression of alpha-V integrins and vitronectin receptor identity in breast cancer cells. Br J Cancer 77: 530-536, 1998

40. Rashidi LH, Homayoni H, Zou X, Liu Land Chen W: Investigation of the strategies for targeting of the afterglow nanoparticles to tumor cells. Photodiagnosis Photodyn Ther 13: 244-254, 2016.

41. Shan D, Li J, Cai P, Prasad P, Liu F, Rauth AM and Wu XY: RGD-conjugated solid lipid nanoparticles inhibit adhesion and invasion of $\alpha_{\mathrm{v}} \beta_{3}$ integrin-overexpressing breast cancer cells. Drug Deliv Transl Res 5: 15-26, 2015.
42. Zeng F, Luo F, Lv S, Zhang H, Cao C, Chen X, Wang S, Li Z, Wang X, Dou X, et al: A monoclonal antibody targeting neuropilin-1 inhibits adhesion of MCF7 breast cancer cells to fibronectin by suppressing the FAK/p130cas signaling pathway. Anticancer Drugs 25: 663-672, 2014.

43. Pal S, Moulik S, Dutta A and Chatterjee A: Extracellular matrix protein laminin induces matrix metalloproteinase-9 in human breast cancer cell line MCF-7. Cancer Microenviron 7: 71-78, 2014.

44. Cao W, Zheng W and Chen T: Ruthenium polypyridyl complex inhibits growth and metastasis of breast cancer cells by suppressing FAK signaling with enhancement of TRAIL-induced apoptosis. Sci Rep 5: 9157, 2015.

45. Tian T, Nan KJ, Guo H, Wang WJ, Ruan ZP, Wang SH, Liang X and Lu CX: PTEN inhibits the migration and invasion of HepG2 cells by coordinately decreasing MMP expression via the PI3K/Akt pathway. Oncol Rep 23: 1593-1600, 2010.

46. Jung CH, Kim EM, Park JK, Hwang SG, Moon SK, Kim WJ and Um HD: Bmall suppresses cancer cell invasion by blocking the phosphoinositide 3-kinase-Akt-MMP-2 signaling pathway. Oncol Rep 9: 2109-2113, 2013.

47. O-charoenrat P, Wongkajornsilp A, Rhys-Evans PH and Eccles SA: Signaling pathways required for matrix metalloproteinase-9 induction by betacellulin in head-and-neck squamous carcinoma cells. Int J Cancer 111: 174-183, 2004.

48. Kane LP, Shapiro VS, Stokoe D and Weiss A: Induction of NF-kappaB by the Akt/PKB kinase. Curr Biol 9: 601-604, 1999.

49. de Mejia EG and Dia VP: Lunasin and lunasin-like peptides inhibit inflammation through suppression of NF-kappaB pathway in the macrophage. Peptides 30: 2388-2398, 2009. 